\title{
Characterizing a Quantum Cascade Tunable Infrared Laser Differential Absorption Spectrometer (QC-TILDAS) for measurements of atmospheric ammonia
}

\author{
R. A. Ellis ${ }^{1}$, J. G. Murphy ${ }^{1}$, E. Pattey ${ }^{2}$, R. van Haarlem ${ }^{2}$, J. M. O'Brien ${ }^{3}$, and S. C. Herndon ${ }^{4}$ \\ ${ }^{1}$ Department of Chemistry, University of Toronto, 80 St. George St., Toronto, ON, M6P 2S1, Canada \\ ${ }^{2}$ Agriculture and Agri-Food Canada, Research Branch, 960 Carling Ave, Ottawa, ON, K1A 0C6, Canada \\ ${ }^{3}$ Environment Canada, Science and Technology Branch, Air Quality Research Division, 4905 Dufferin St., Toronto, ON, \\ M3H 5T4, Canada \\ ${ }^{4}$ Aerodyne Research Inc., 45 Manning Road, Billerica, MA, 01821-3976, USA
}

Received: 14 November 2009 - Published in Atmos. Meas. Tech. Discuss.: 16 December 2009

Revised: 12 March 2010 - Accepted: 23 March 2010 - Published: 30 March 2010

\begin{abstract}
A compact, fast-response Quantum Cascade Tunable Infrared Laser Differential Absorption Spectrometer (QC-TILDAS) for measurements of ammonia $\left(\mathrm{NH}_{3}\right)$ has been evaluated under both laboratory and field conditions. Absorption of radiation from a pulsed, thermoelectrically cooled QC laser occurs at reduced pressure in a $0.5 \mathrm{~L}$ multiple pass absorption cell with an effective path length of $76 \mathrm{~m}$. Detection is achieved using a thermoelectrically-cooled Mercury Cadmium Telluride $(\mathrm{HgCdTe})$ infrared detector. A novel sampling inlet was used, consisting of a short, heated, quartz tube with a hydrophobic coating to minimize the adsorption of $\mathrm{NH}_{3}$ to surfaces. The inlet contains a critical orifice that reduces the pressure, a virtual impactor for separation of particles, and additional ports for delivering $\mathrm{NH}_{3}$ free background air and calibration gas standards. The level of noise in this instrument has been found to be $0.23 \mathrm{ppb}$ at $1 \mathrm{~Hz}$. The sampling technique has been compared to the results of a conventional lead salt Tunable Diode Laser Absorption Spectrometer (TDLAS) during a laboratory intercomparison. The effect of humidity and heat on the surface interaction of $\mathrm{NH}_{3}$ with sample tubing was investigated at mixing ratios ranging from $30-1000 \mathrm{ppb}$. Humidity was seen to worsen the $\mathrm{NH}_{3}$ time response and considerable improvement was observed when using a heated sampling line. A field intercomparison of the QC-TILDAS with a modified Thermo 42CTL chemiluminescence-based analyzer was also performed at Environment Canada's Centre for Atmospheric
\end{abstract}

Correspondence to: J. G. Murphy

(jmurphy@chem.utoronto.ca)
Research Experiments (CARE) in the rural town of Egbert, ON between May-July 2008. Background tests and calibrations using two different permeation tube sources and an $\mathrm{NH}_{3}$ gas cylinder were regularly carried out throughout the study. Results indicate a very good correlation at $1 \mathrm{~min}$ time resolution $\left(R^{2}=0.93\right)$ between the two instruments at the beginning of the study, when regular background subtraction was applied to the QC-TILDAS. An overall good correlation of $R^{2}=0.85$ was obtained over the entire two month data set, where the majority of the spread can be attributed to differences in inlet design and background subtraction methods.

\section{Introduction}

Ammonia $\left(\mathrm{NH}_{3}\right)$ is the most abundant alkaline gas in the atmosphere and plays an important role in many atmospheric processes. The majority of $\mathrm{NH}_{3}$ emissions to the atmosphere arise from agricultural activities, such as application of fertilizer and volatilization from animal wastes (Pinder et al., 2006; Erisman et al., 2008). Other sources include light duty gasoline vehicles equipped with three-way catalytic converters, water and sewage treatment plants, and chemical production plants (Zhang et al., 2008; Livingston et al., 2009). Once in the atmosphere, $\mathrm{NH}_{3}$ can either be deposited to land, vegetation or water bodies adjacent to the emission source areas or undergo atmospheric reactions with acids formed from the oxidation of sulfur dioxide $\left(\mathrm{SO}_{2}\right)$ and nitrogen oxides $\left(\mathrm{NO}_{\mathrm{X}}\right)$. In the presence of these acids, $\mathrm{NH}_{3}$ can contribute to the formation of fine particulate matter $\left(\mathrm{PM}_{2.5}\right)$ with strong implications for human health (Pope et al., 2002)

Published by Copernicus Publications on behalf of the European Geosciences Union. 
and radiative forcing (IPCC, 2007). Particulate ammonium $\left(\mathrm{NH}_{4}\right)$ has a longer atmospheric lifetime than $\mathrm{NH}_{3}$ and can therefore be transported over relatively long distances. Deposition of particulate phase $\mathrm{NH}_{4}$ (and gas phase $\mathrm{NH}_{3}$ ) can fertilize nitrogen-limited ecosystems or cause eutrophication in nitrogen-saturated ecosystems, as well as cause acidification of soils (Asman et al., 1998; Krupa, 2003; Galloway et al., 2003). North American regulatory policies put in place to control $\mathrm{PM}_{2.5}$ levels have largely focused on reductions in emissions of $\mathrm{SO}_{2}$ and $\mathrm{NO}_{\mathrm{x}}$. Recent modeling studies have explored the effectiveness of $\mathrm{NH}_{3}$ emission reductions on the $\mathrm{PM}_{2.5}$ mass loadings in North America. Pinder et al. (2007) found that a $10 \%$ reduction in $\mathrm{NH}_{3}$ emissions decreased $\mathrm{PM}_{2.5}$ by $1.4 \%$ in the summer and $5.7 \%$ in the winter in the Eastern US, and that $\mathrm{NH}_{3}$ emission reductions are often more cost-effective than $\mathrm{SO}_{2}$ and $\mathrm{NO}_{\mathrm{x}}$ controls. North America wide reductions of agricultural $\mathrm{NH}_{3}$ emissions by $30 \%$ were found to decrease average $\mathrm{PM}_{2.5}$ by $0-7 \%$ but decreases in the 95th percentile could be up to a factor of six larger (Makar et al., 2009). Due to its environmental impacts, it is important to be able to predict the emissions and chemical transformations of $\mathrm{NH}_{3}$ in the environment, but a lack of accurate in-situ measurements of $\mathrm{NH}_{3}$ makes it difficult to constrain models and produce more precise emission factors for inventories.

One reason for the paucity of measurements in the past has been the absence of sampling and analytical techniques which are accurate, robust, and inexpensive. Traditional methods of measuring $\mathrm{NH}_{3}$ involve the use of passive filters and denuders with long integration time and offline analysis, which often suffer from chemical interferences and are usually labour-intensive (Wiebe et al., 1990; Fehsenfeld et al., 2002). Chemiluminescence-based instruments offer higher time resolution, but this indirect method is prone to interferences and false positives (Winer et al., 1974; Dunlea et al., 2007; Steinbacher et al., 2007). More recent techniques involve the use of spectroscopic instruments and chemical ionization mass spectrometry (CIMS), which provide high time resolution and are both specific and sensitive to $\mathrm{NH}_{3}$, but are often expensive and challenging to deploy in field conditions (Li et al., 2006; Nowak et al., 2007; Whitehead et al., 2007). A summary of instrument figures of merit for different $\mathrm{NH}_{3}$ measurement techniques can be found in von Bobrutzki et al. (2010). Recent field intercomparisons involving $\mathrm{NH}_{3}$ analyzers based on more traditional methods and newer analytical techniques indicate that many challenges remain in obtaining accurate $\mathrm{NH}_{3}$ measurements (Norman et al., 2009; von Bobrutzki et al., 2010). The performance of any state of the art instrument is limited by the sampling efficiency. $\mathrm{NH}_{3}$ is highly water soluble and can readily be adsorbed on any surface in contact with the sample air flow, such as filters, inner walls of inlet tubing, and analyzer parts. Thus, designing a sampling inlet that minimizes interactions of $\mathrm{NH}_{3}$ with surfaces is essential in making accurate measurements. The sampling method should also be selective against particles, especially for volatile salts such as ammonium nitrate $\left(\mathrm{NH}_{4} \mathrm{NO}_{3}\right)$ and ammonium chloride $\left(\mathrm{NH}_{4} \mathrm{Cl}\right)$ which may volatilize prior to detection and produce a positive bias for ambient $\mathrm{NH}_{3}$ (Gras, 1984; Cheng and Tsai, 1997; Chow et al., 1998).

We present the results from two intercomparisons between a Quantum Cascade Tunable Infrared Laser Differential Absorption Spectrometer (QC-TILDAS, Aerodyne Research, Inc., Billerica, Massachusetts) and a Tunable Diode Laser Absorption Spectrometer (TDLAS, model TGA-100, Campbell Scientific, Logan, Utah) and between the QCTILDAS and a chemiluminescence-based instrument (modified Thermo 42CTL, Thermo Scientific, Franklin, Massachusetts). The first analyzer intercomparison examines the impact of heating the sampling line and of changing ambient humidity on $\mathrm{NH}_{3}$ adsorption. The second analyzer intercomparison examines environmental effects (ambient relative humidity and temperature) on the measurement of ambient $\mathrm{NH}_{3}$.

\section{Experimental methods}

\subsection{Quantum cascade laser absorption spectroscopy}

Laser absorption spectroscopy is a powerful method of analysis for atmospheric trace gases with resolvable rotationalvibrational absorption features, especially in the midinfrared region containing the stronger fundamental vibrational bands. The QC-TILDAS determines the mixing ratio of $\mathrm{NH}_{3}$ by monitoring the molecule's absorption of radiation at $967 \mathrm{~cm}^{-1}$. The system uses a thermoelectrically cooled quantum cascade (QC) laser (Alpes Lasers, Neuchatel, Switzerland) operating in the pulsed mode to provide high stability and increased power output over traditional lead-salt diode lasers (McManus et al., 2002). A layout of the optical table can be found in McManus et al. (2007). The laser output is directed into an astigmatic Herriott type multiple pass absorption cell $(0.5 \mathrm{~L}, 76 \mathrm{~m}$ effective path length), the inside of which is coated with a hydrophobic fluorinated silane coating in order to limit the interactions of $\mathrm{NH}_{3}$ with cell walls. The optical system also includes a reference path whose primary function is to serve as a pulse normalization leg in order to reduce the spectral noise from pulse-to-pulse amplitude variation. This is achieved by dividing the absorption spectrum (obtained from $\sim 150$ individual laser pulses) by the pulse normalization reference spectrum. Periodically, the reference path is directed through a $5 \mathrm{~cm}$ cell containing ethylene $\left(\mathrm{C}_{2} \mathrm{H}_{4}\right)$, a less surface reactive gas with a molecular line in the same region as $\mathrm{NH}_{3}$, which can be used for absorption-line lock. If the laser line position drifts between reference locks, a small correction is applied to the laser temperature to bring the laser line back into position. Another role for the reference path is to measure the laser tuning rate by inserting a germanium etalon in the laser path. 
Both the signal and reference paths are focused onto a thermoelectrically cooled HgCdTe infrared detector (Vigo Systems, Poland) and temporally separated by $250 \mathrm{~ns}$, the time required to traverse the multiple pass absorption cell.

The software package TDLWintel, developed by Aerodyne Research Inc, drives the QC laser, retrieves, analyzes and stores spectra, and calculates and stores mixing ratios. The laser frequency is swept across the full molecular transition at $967.34 \mathrm{~cm}^{-1}$ and the resulting spectrum is fit by convolving the laser line shape with an absorption line shape calculated from the HITRAN (high-resolution transmission) molecular absorption database and the measured pressure, temperature and path length of the absorption cell (Herndon et al., 2007). Other trace gases that absorb in the same region as $\mathrm{NH}_{3}$ are ethylene (at $967.33 \mathrm{~cm}^{-1}$ ) and methanol $\left(\mathrm{CH}_{3} \mathrm{OH}\right.$, at $\left.967.36 \mathrm{~cm}^{-1}\right)$, which both have weak absorption lines and are not expected to be present in high quantities in the atmosphere. However, if these species were to cause interference with the $\mathrm{NH}_{3}$ absorption spectrum, the TDLWintel software allows the operator to refit saved spectra for several different species. The software also controls the additions of calibration gas and background gas at userdefined time intervals through the use of two solenoid valves. One of the benefits of software-controlled background addition is the ability to perform automatic background subtractions. TDLWintel sends a signal to automatically open a solenoid valve, allowing $\mathrm{NH}_{3}$-free air to flush the inlet, and measures the resulting spectrum for a specified period of time. The flushing period ranges from $30 \mathrm{~s}$ to several minutes and can be adjusted depending on the environmental conditions (ambient $\mathrm{NH}_{3}$ mixing ratio, humidity). Only the last $1 / 3$ of the measurements made during the flushing period are used for the background. The software then subtracts this background spectrum from all subsequent spectra, providing a flatter baseline for the fit. Further description of the optical design and data acquisition system of the QC-TILDAS can be found in Nelson et al. (2004).

\subsection{Instrument figures of merit}

\subsubsection{Accuracy}

While absorption spectroscopy is theoretically an absolute technique when the absorption cross section is known, external calibrations of the QC-TILDAS system indicated underestimation of the $\mathrm{NH}_{3}$ mixing ratio that depended on the laser output voltage. When comparing to the TDLAS, the measurements obtained by the QC-TILDAS were approximately two times lower when the QC laser was being operated moderately high above threshold (by $\sim 2 \mathrm{~V}$ ). During the field intercomparison, we found about the same factor to hold true under similar laser parameters. It was also discovered that by tuning the laser output voltage down close to threshold, the QC-TILDAS would report mixing ratios closer to the calculated calibration values. Figure 1 shows a series of multiple point calibrations performed throughout the two month field study at Egbert, ON. The calibrations can be separated into two groups, one with an average slope of 0.42 and one with an average slope of 0.66 . The difference in slopes is due to changes in laser voltage, which in turn affects the retrieved $\mathrm{NH}_{3}$ spectrum as shown in Fig. $1 \mathrm{~b}$ and c. In these plots, the green spectrum is the average of 100 observed $\mathrm{NH}_{3}$ spectra and the blue lines are the baseline and spectral fit calculated based on the HITRAN database and measured temperature, pressure and laser line width. In panel (b), a spectrum taken at high laser output voltage is shown to have considerable laser line shape distortion and increased laser line width, while the spectrum in panel (c), taken at low laser output voltage exhibits less distortion. The spectral fit shown in blue is based on a Voigt line shape which cannot duplicate the line shape distortion, thus resulting in an underestimation of the $\mathrm{NH}_{3}$ calibration mixing ratio. It has been reported previously that laser line distortion occurs in QCLs that are operated high above threshold due to transient heating during the laser pulse (Nelson et al., 2002; Grouiez et al., 2009). The issue may be alleviated by keeping the laser near threshold, but it is done so at the expense of reduced signal to noise. However, since the distortion and underestimation is constant at any given laser output voltage, we can resolve the issue through frequent calibrations. Data from the two intercomparisons in the following sections has been corrected for line shape distortion in this manner.

\subsubsection{Precision}

In systems that are mainly dominated by random instrument noise, the detection limit can be predicted by the Allan variance (Werle et al., 1993). Figure 2 displays $1 \mathrm{~Hz}$ measurements of $4.2 \mathrm{ppb} \mathrm{NH}_{3}$ from a $1.9 \mathrm{ppm} \mathrm{NH}_{3}$ gas cylinder diluted with zero air in the upper panel and the Allan variance plot for this data in the lower panel. This is a typical mixing ratio of $\mathrm{NH}_{3}$ in ambient air away from major sources and was used to estimate the instrument detection limit at low mixing ratios. The amount of noise in a $1 \mathrm{~Hz}$ measurement is 230 ppt. Using the standard definition of detection limit ( $3 \sigma$ of the signal) we estimate a detection limit of $690 \mathrm{ppt}$, where $\sigma$ is the standard deviation retrieved from the Allan plot. The linearly decreasing part of the Allan plot is dominated by white noise, and further averaging of data in this region will result in a decrease in noise. With an averaging time of $60 \mathrm{~s}$, the detection limit estimated from the Allan variance decreases to $100 \mathrm{ppt}$. The minimum point in the Allan plot is the optimum integration time $(\sim 300 \mathrm{~s})$, which leads to a detection limit of 42 ppt. Instrumental drift begins to dominate beyond the optimum integration time, and further averaging of the data will not lead to a decrease in noise. 


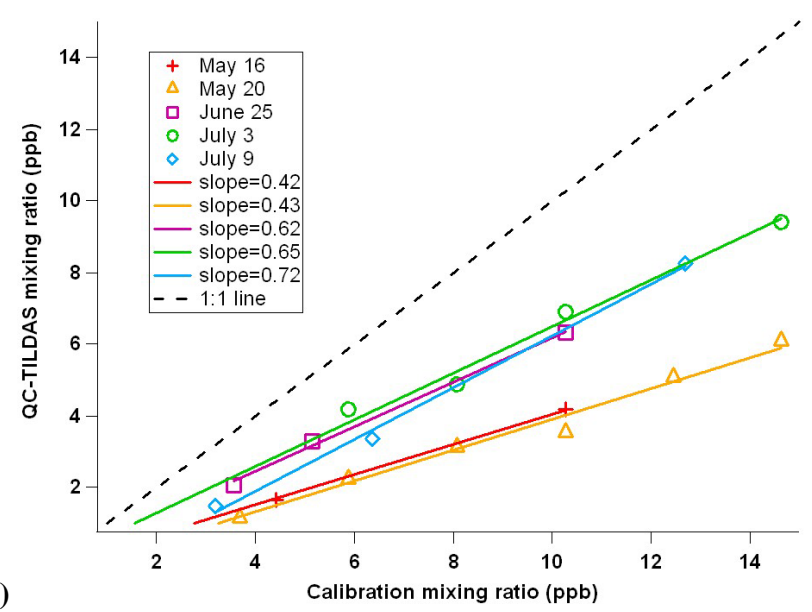

(a)

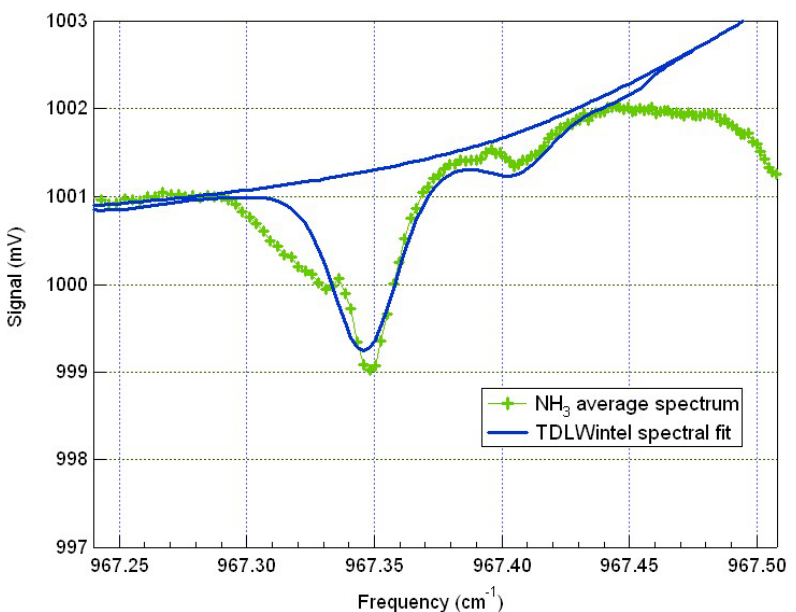

(b)

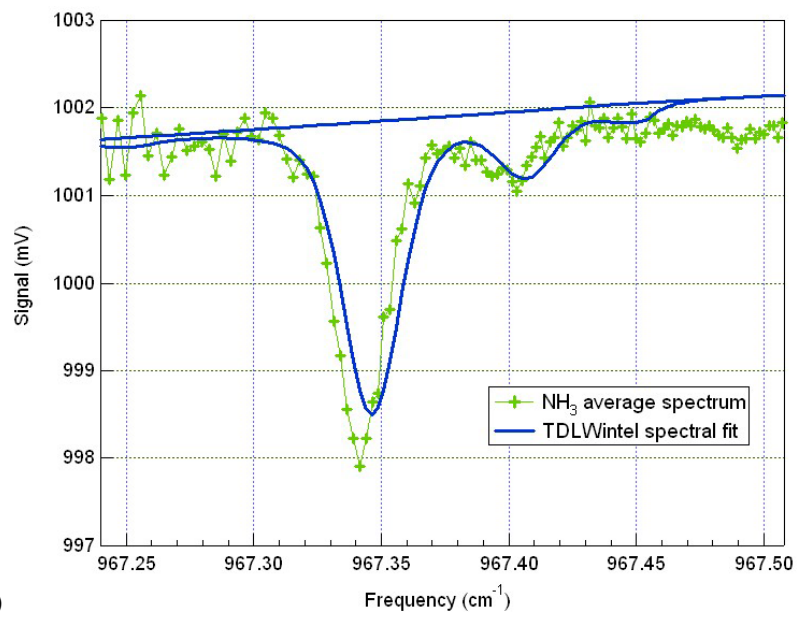

Fig. 1. Multiple point calibrations (a) performed throughout the two month field study indicate QC-TILDAS is underestimating $\mathrm{NH}_{3}$. Spectra retrieved at high laser output power (b) exhibit considerable laser line shape distortion resulting in calibration slope of $\sim 0.42$ and spectra exhibiting little distortion but increased noise (c) at low laser output power result in an average calibration slope of 0.66 .

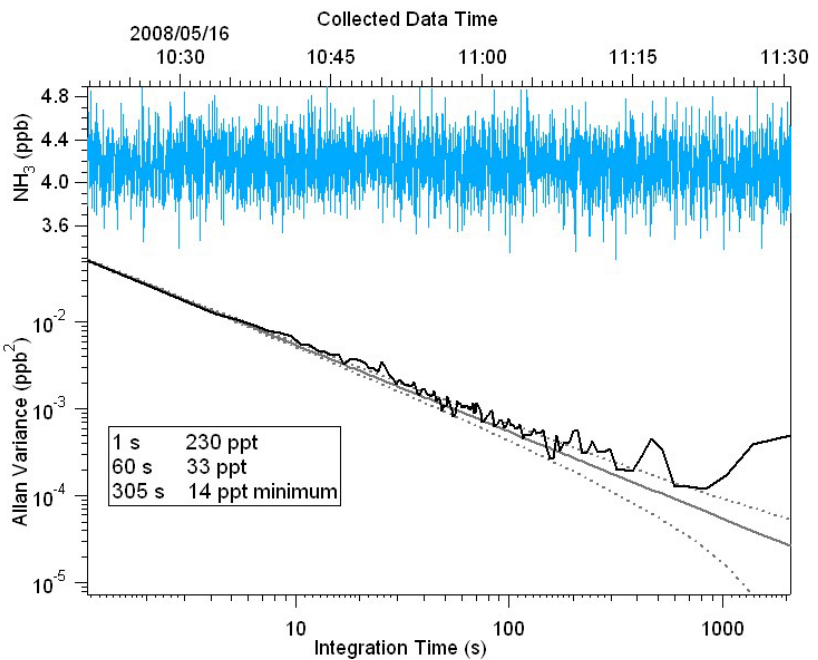

Fig. 2. Instrument noise and detection limit can be estimated using an Allan variance plot. Upper trace displays a one hour long measurement from an $\mathrm{NH}_{3}$ gas cylinder at $1 \mathrm{~Hz}$; lower trace shows the Allan variance for the data set with $230 \mathrm{ppt}$ of noise in $1 \mathrm{~s}$ and a minimum of $14 \mathrm{ppt}$ noise with approximately $5 \mathrm{~min}$ averaging. The detection limit can be defined as $3 *$ noise and is equal to $690 \mathrm{ppt}$ at $1 \mathrm{~Hz}$.

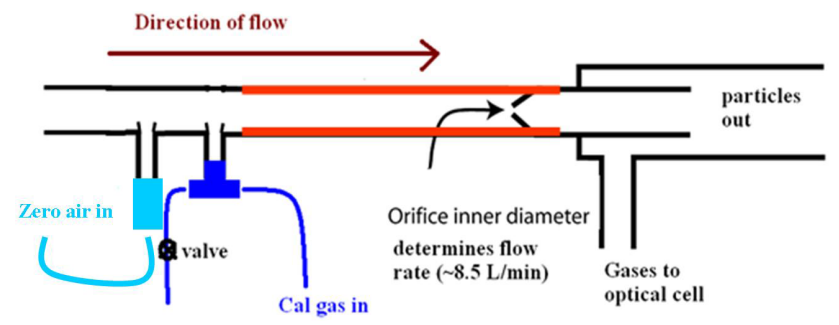

Fig. 3. Schematic of QC-TILDAS quartz inlet outlining the locations of background and calibration ports, critical orifice and virtual impactor. The red lines indicate heating of the inlet to $40^{\circ} \mathrm{C}$.

\subsection{Inlet design}

The first step in achieving accurate atmospheric measurements of $\mathrm{NH}_{3}$ is using a sampling setup that reduces gas interactions with surfaces. Figure 3 illustrates the sample inlet used by the QC-TILDAS in this work. A short $(10 \mathrm{~cm})$, quartz inlet, originally designed by Aerodyne Research Inc., is internally coated with a fluorinated silane coating and heated to $40 \pm 2{ }^{\circ} \mathrm{C}$ to limit condensation of water and the interaction of $\mathrm{NH}_{3}$ with inlet surfaces. A critical orifice keeps a constant flow of $\sim 9 \mathrm{~L} \mathrm{~min}^{-1}$ (measured upstream at $101.3 \mathrm{kPa}$ and $298 \mathrm{~K}$ ) and drops the pressure in the sampling line and optical cell to $5.3-8 \mathrm{kPa}$, which further minimizes $\mathrm{NH}_{3}$ adsorption effects (Warland et al., 2001). Following the critical orifice, the flow is split into two branches with approximately $90 \%$ of the flow making a sharp turn and being pulled through the optical cell. The other $10 \%$ is pulled 
directly to the pump, relying on inertia to remove more than $50 \%$ of particles larger than $300 \mathrm{~nm}$. Analytical techniques that do not separate the particulate and gas phase may suffer from a positive bias if ammonium produces an $\mathrm{NH}_{3}$ signal (Gras, 1984; Cheng and Tsai, 1997; Chow et al., 1998). In the case of the QC-TILDAS, this could occur if $\mathrm{NH}_{4} \mathrm{NO}_{3}$ or $\mathrm{NH}_{4} \mathrm{Cl}$ volatilized in the sampling line or optical cell prior to detection. However, the use of a filter to remove particles can also lead to volatilization of $\mathrm{NH}_{4}$ particles from the filter surface along with loss of $\mathrm{NH}_{3}$ to the filter surface, which can then be re-volatilized and lead to complicated results. The inlet design shown in Fig. 3 eliminates the use of filters and any interference they may cause while still protecting the optical cell mirrors. Two additional ports are used for the introduction of calibration gas and $\mathrm{NH}_{3}$-free background gas, designed so that these flows encounter the inlet in the same way as ambient sampling. Background gas used for these experiments was either in the form of zero air or nitrogen from a cylinder. A solenoid valve in line between the background gas source and inlet is normally closed and opens automatically during the background cycle to slightly overflow the inlet with approximately $11 \mathrm{~L} \mathrm{~min}^{-1}$ of gas, ensuring that ambient air does not enter the inlet during that time. The QC-TILDAS calibration setup includes a $\mathrm{NH}_{3}$ permeation tube source (KIN-TEK, La Marque, Texas) producing $\sim 150 \mathrm{ng} \min ^{-1} \mathrm{NH}_{3}$ that is kept continuously flowing at a low rate $\left(\sim 0.5 \mathrm{~L} \mathrm{~min}^{-1}\right)$ so that the surfaces on the inside of the calibration lines are sufficiently coated. A solenoid valve in line between the inlet and an external pump is kept normally open and will close automatically during the calibration cycle, causing the calibration gas to enter the inlet. This setup decreases the time required to reach stabilization during calibrations to $1 \mathrm{~min}$ or less. Calibration is usually performed every $2 \mathrm{~h}$ for $5 \mathrm{~min}$, but is dependant on the stability of the system with regards to temperature and laser output voltage.

\subsection{Inlet tests}

In order to accurately measure $\mathrm{NH}_{3}$ in the atmosphere, one needs to overcome the challenge of adsorption of this sticky gas to inlet walls and sampling lines. The sampling efficiency of the inlet described above was tested during an intercomparison between the QC-TILDAS and the TDLAS at the Ottawa Research Centre of Agriculture and Agri-Food Canada. Several experiments were carried out in a controlled laboratory environment in order to test the response of the instruments to a range of $\mathrm{NH}_{3}$ mixing ratios using both humid ambient air and dry nitrogen and with the use of a heated sampling line. The TDLAS and QC-TILDAS have similar modes of operation, except that the TDLAS uses cryogenic cooling for both the laser and detector and a single-pass absorption cell. Both instruments were fitted with the quartz inlet described above and operated at a data acquisition rate of $10 \mathrm{~Hz}$ in order to capture fast time responses. Calibration gas was produced using a $4 \mathrm{ppm} \mathrm{NH}_{3}$ cylinder diluted with nitrogen resulting in a range of mixing ratios between 30 and $1000 \mathrm{ppb}$. Each mixing ratio was sampled for 15 minutes, followed by 15 min sampling of room air or nitrogen. Experiments were run using humid (RH $\sim 60-65 \%)$ and dry air with either a heated or unheated PFA-Teflon sampling line between the inlet and absorption cell.

The decrease in the mixing ratio of $\mathrm{NH}_{3}$ was wellrepresented by a bi-exponential decay of the form:

$y=y_{0}+A_{1} \exp \left(\frac{-\left(t-t_{0}\right)}{\tau_{1}}\right)+A_{2} \exp \left(\frac{-\left(t-t_{0}\right)}{\tau_{2}}\right)$

where $A_{1}$ and $A_{2}$ are constants and their sum is equal to the stable mixing ratio of $\mathrm{NH}_{3}$ prior to the calibration flow being switched off; $y_{0}$ is equal to the $\mathrm{NH}_{3}$ mixing ratio reached at the end of the decay; $t$ is time and $t_{0}$ is the time at the start of the fit; $\tau_{1}$ and $\tau_{2}$ are time decay constants, the first of which is fast and corresponds to the gas exchange time of the system, and the second being much slower and corresponding to interactions of $\mathrm{NH}_{3}$ with surfaces on the interior surfaces of the inlet, sampling lines and absorption cell.

\subsection{Field intercomparison}

Field measurements took place between May and July 2008 at Environment Canada's Centre for Atmospheric Research

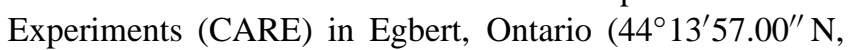
$79^{\circ} 46^{\prime} 53.00^{\prime \prime} \mathrm{W}$, elevation $253 \mathrm{~m}$ ). The facility is situated in a rural agricultural and forested region approximately $80 \mathrm{~km}$ northwest of Toronto, Ontario, Canada. The QC-TILDAS was operated alongside a modified Thermo 42CTL $\mathrm{NO}_{\mathrm{y}}$ chemiluminescence-based analyzer for the duration of the study. The principle of operation of the Thermo 42CTL is based on the difference in the amount of reactive nitrogen species converted to nitrogen oxide (NO) over both a stainless steel converter at $750^{\circ} \mathrm{C}$ and a molybdenum converter at $325^{\circ} \mathrm{C}$ and the amount converted to $\mathrm{NO} 325^{\circ} \mathrm{C}$ over just a molybdenum converter. This difference is attributed to the ambient $\mathrm{NH}_{3}$ mixing ratio. The flow rate for the Thermo 42CTL was approximately $1 \mathrm{~L} \mathrm{~min}^{-1}$ through a short $15 \mathrm{~cm}$ inlet containing a filter to separate particles. In efforts to minimize any possible interference from $\mathrm{NH}_{4} \mathrm{NO}_{3}$ volatilization, the inlet filter for the Thermo 42CTL was changed daily. The QC-TILDAS sampled ambient air at $8.7 \mathrm{~L} \mathrm{~min}^{-1}$ through the quartz inlet described previously with a $3 \mathrm{~m}$ length of TeflonPFA line between the inlet and the optical cell. The sampling frequencies were $1 \mathrm{~s}$ for the QC-TILDAS and a $1 \mathrm{~min}$ averaging time was reported for the Thermo 42CTL. Hourly averages of ambient temperature, relative humidity, wind direction, wind speed and precipitation data were also obtained at CARE.

Multiple point calibrations were carried out periodically using a $1.9 \mathrm{ppm} \mathrm{NH}_{3}$ gas cylinder diluted with gas from a zero air generator to produce a range of mixing ratios between 1-15 ppb. One point calibrations were also performed 
using two different permeation tube sources (KIN-TEK and VICI Metronics, Poulsbo, Washington). Backgrounds were measured by flushing the inlets with nitrogen gas or with air produced from a zero air generator (API, San Diego, California). The QC-TILDAS also performed periodic automatic backgrounds during the course of the study. The automatic background was set to flush the inlet with background gas for $1 \mathrm{~min}$ every $15 \mathrm{~min}$. However, the cycle was changed to providing background gas to the inlet for 10 min every $2 \mathrm{~h}$ due to the suspicion that not all $\mathrm{NH}_{3}$ was being flushed from the system using the shorter cycle duration. This was adopted as the best compromise between performing frequent backgrounds that capture changes in the spectral baseline and ensuring that air sampled during background checks is $\mathrm{NH}_{3}$-free.

\section{Results and discussion}

\subsection{Laboratory intercomparison of QC-TILDAS and TDLAS}

The two laser absorption spectrometers were compared during a laboratory study at the Agriculture and Agri-Food Canada Ottawa Research Centre for one week in July 2008. Calibration of both instruments was performed simultaneously using a range of $\mathrm{NH}_{3}$ mixing ratios from $30-1000 \mathrm{ppb}$. Very good correlation was obtained at $10 \mathrm{~Hz}$ between the QC-TILDAS and TDLAS with $R^{2}=0.91$ over the entire dataset from $0-1 \mathrm{ppm}$. Some of the spread can be explained by slight differences between the two instruments' computer clocks, making it difficult to exactly match the data at $10 \mathrm{~Hz}$. In addition, optical fringing in the TDLAS caused a baseline interference of $50 \mathrm{ppb}$ and fluctuations at mixing ratios lower than $100 \mathrm{ppb}$, which further contributed to the scatter. As TDLAS is mostly used to make $\mathrm{NH}_{3}$ flux measurements in agricultural regions, where the $\mathrm{NH}_{3}$ mixing ratios can reach ppm levels, we focused on the comparison of the two instruments at higher $\mathrm{NH}_{3}$ levels. Figure 4a illustrates the response of both instruments to a step change from ambient to $350 \mathrm{ppb} \mathrm{NH}_{3}$, a typical mixing ratio found close to sources such as recently fertilized fields and livestock farms. The majority ( $>90 \%$ ) of the increase occurs in a few seconds and both instruments reach a stable reading within the $15 \mathrm{~min}$ time period. A similar study by Schwab et al. (2007) that investigated the response to $\mathrm{NH}_{3}$ step changes using mixing ratios between 5-40 ppb found that most instruments in the study required several hours to reach a stable reading. Allan variance analysis was performed on the time period indicated in red in Fig. 4a for both instruments and results are given in Fig. 4b. For a mixing ratio of $350 \mathrm{ppb}$, the amount of noise $(1 \sigma)$ in a $10 \mathrm{~Hz}$ measurement for the QC-TILDAS was $3.15 \mathrm{ppb}$ and for the TDLAS was $7.30 \mathrm{ppb}$. For $1 \mathrm{~s}$ averaging of the $10 \mathrm{~Hz}$ data the QC-TILDAS standard deviation from the Allan variance analysis was $1.11 \mathrm{ppb}$ and for the TDLAS $1.89 \mathrm{ppb}$. The optimum integration time for the QC-

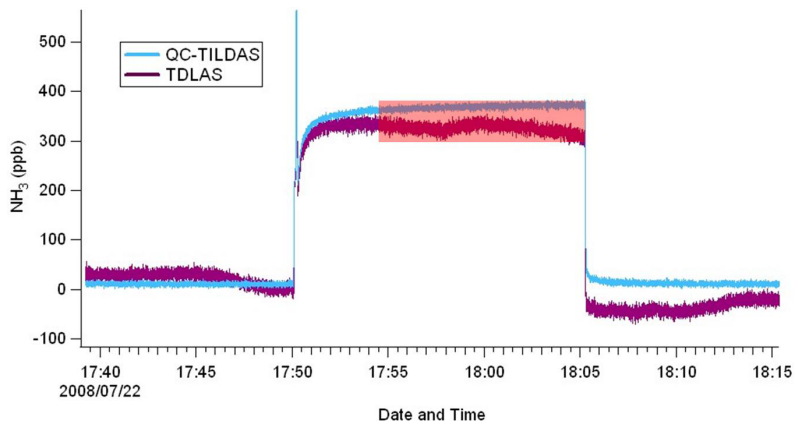

(a)

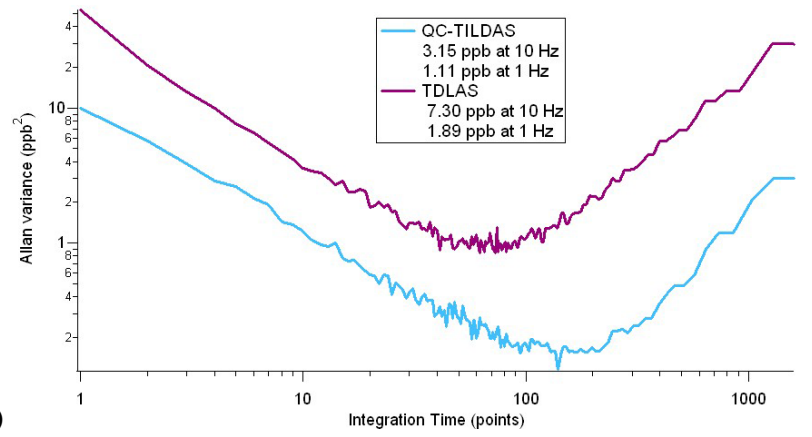

Fig. 4. (a) shows the time response at $10 \mathrm{~Hz}$ of the QC-TILDAS and

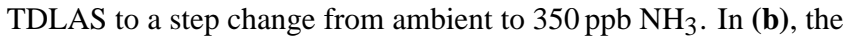
Allan variance for both instruments is displayed for the ten minute period highlighted in red in panel (a).

TILDAS $(\sim 130 \mathrm{~s})$ yielded a minimum noise level of $0.34 \mathrm{ppb}$ while the optimum integration time for the TDLAS $(\sim 60 \mathrm{~s})$ resulted in a minimum of $0.92 \mathrm{ppb}$. Further averaging beyond the optimum integration time does not result in a decrease in noise due to the increase in instrumental drift. From the Allan variance plot, we observe that the QC-TILDAS achieves lower noise levels under these conditions and is less susceptible to instrument drifts.

\subsection{Sampling line effects}

Several studies have investigated the adsorption of $\mathrm{NH}_{3}$ to different types of sample inlet materials at various temperatures (Yokelson et al., 2003; Shah et al., 2006; Whitehead et al., 2008). In our laboratory intercomparison between the QC-TILDAS and the TDLAS, we examined the effect of heat and humidity on $\mathrm{NH}_{3}$ adsorption to sampling lines. The results from the bi-exponential decay analysis for the QCTILDAS are presented in Fig. 5. Here we define a term $D$ that refers to the fraction of the total loss of $\mathrm{NH}_{3}$ that corresponds to the second (slow) exponential term in Eq. (1). It is described mathematically as:

$$
D=\frac{A_{2}}{\left(A_{1}+A_{2}\right)} \times 100
$$

where $A_{1}$ and $A_{2}$ are the pre exponential constants described in Eq. (1). The relative contributions of surface interactions 


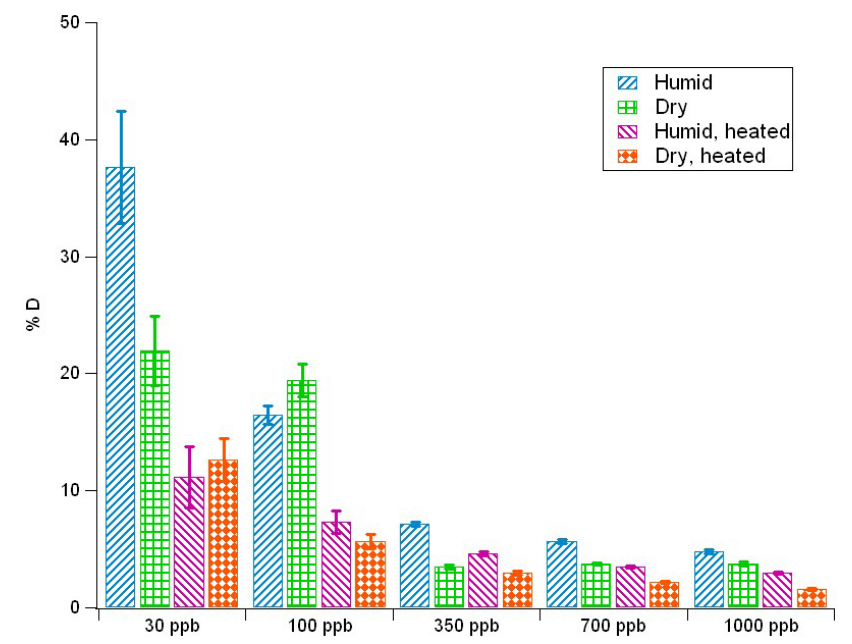

Fig. 5. D-factor illustrates the extent of $\mathrm{NH}_{3}$ surface interaction at a range of $\mathrm{NH}_{3}$ mixing ratios under conditions of dry and humidified air and using a heated line. The relative contribution of surface interactions is higher at lower mixing ratios, under humid conditions and without the use of a heated line. Error bars indicate one standard deviation.

are larger when the value of $D$ is higher, since a higher $D$ signifies that the second term in the bi-exponential decay given in Eq. (1), which is related to interaction of $\mathrm{NH}_{3}$ with surfaces, is more prominent. For the QC-TILDAS, $\tau_{1}$ was on the order of $0.4 \mathrm{~s}$, and $\tau_{2}$ was on the order of $15 \mathrm{~s}$. In a similar study by Whitehead et al. (2008) where the time response of an older model quantum cascade laser absorption spectrometer was investigated, $\tau_{1}$ was found to be on the order of $2 \mathrm{~s}$.

Several deductions can be made from Fig. 5; first, there is a noticeable difference between the $D$ factor at the lowest mixing ratio of $30 \mathrm{ppb}$ to the highest (1000 ppb), indicating differences in the relative importance of $\mathrm{NH}_{3}$ surface interactions at low and high mixing ratios. The PFA-Teflon polymer sampling line has a finite number of adsorption sites, which quickly fill up in the presence of high mixing ratios of $\mathrm{NH}_{3}$, allowing subsequent molecules to pass freely with little to no surface interaction. At lower mixing ratios, with fewer molecules per any given surface area, a greater fraction of molecules will interact with the surface and undergo adsorption effects, increasing the $D$ factor and thus the time required for all molecules to de-sorb from the polymer surface. Our observations are qualitatively consistent with Mukhtar et al. (2003), who examined $\mathrm{NH}_{3}$ adsorption to PFA-Teflon and low density polyethylene (LDPE) at much higher mixing ratios. The second detail we observe from Fig. 5 is that the $D$ factor is generally lower for experiments performed in dry nitrogen than in humid room air. This suggests that there is less interaction between $\mathrm{NH}_{3}$ and inner tubing surfaces when those surfaces are dry. Since $\mathrm{NH}_{3}$ is known to form strong hydrogen bonds with water, we expect increased adsorption

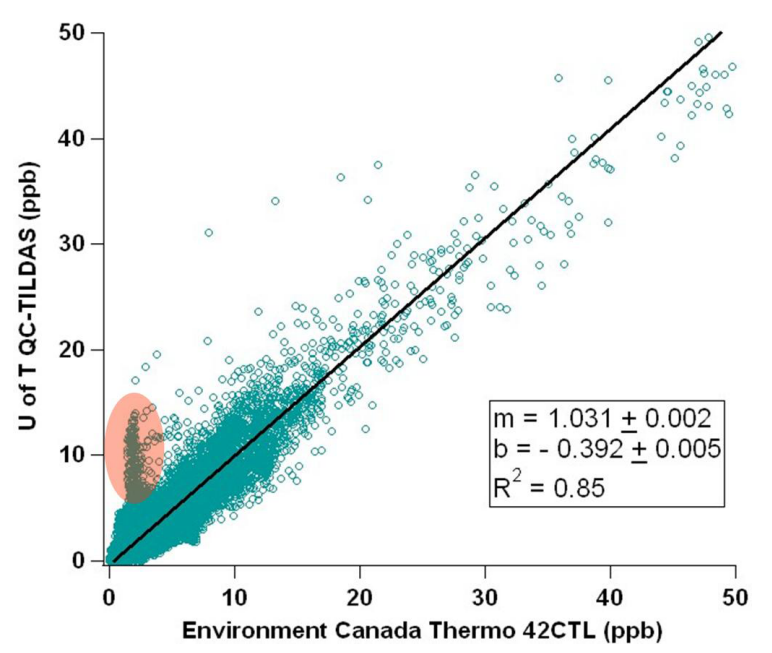

Fig. 6. Correlation plot of the QC-TILDAS and Thermo 42CTL. Most of the scatter can be explained by differences in inlet design and background subtraction methods. The time period outlined in red is shown in Fig. 7b.

if a surface is coated with water, as observed. A significant improvement was observed when using a heated line held at a constant $40{ }^{\circ} \mathrm{C}$ between the inlet and the optical cell, reducing the relative contributions of surface interactions in the overall decay to $\sim 10 \%$ at the lowest concentration of $30 \mathrm{ppb}$. Heating the line decreases the $\mathrm{NH}_{3}$ adsorption to the surface, possibly by reducing the presence of condensed water inside the sampling line.

\subsection{Field intercomparison}

The QC-TILDAS was compared with a modified Thermo 42CTL chemiluminescence instrument at Environment Canada's Centre for Atmospheric Research Experiments (CARE) between 7 May and 18 July 2008. Ambient temperatures during this time were highly variable ranging from $0^{\circ} \mathrm{C}$ to $32^{\circ} \mathrm{C}$. The relative humidity was approximately $40 \%$ during the day at the beginning of the study and close to $60 \%$ during the months of June and July. At night, the RH was very high, between $90-100 \%$. Figure 6 displays a correlation plot between the QC-TILDAS and Thermo 42CTL. The correlation plot was obtained using an iterative bivariate least squares method that takes into account errors in both $\mathrm{x}$ and $\mathrm{y}$, as described by Cantrell (2008). Overall good correlation was achieved for the study with a slope of $1.031 \pm 0.002, R^{2}$ of 0.85 and offset of $-0.392 \pm 0.005$ using $1 \mathrm{~min}$ averaged data. Some of the scatter may be explained by differences in the $\mathrm{NH}_{3}$ mixing ratio measured due the type of inlet used. Adsorption-desorption effects and differences in inlet time response can cause discrepancies between different $\mathrm{NH}_{3}$ analyzers, especially at lower mixing ratios (von Bobrutzki et al., 2010). Figure 7a demonstrates one example of instrument time response to fast changes in 


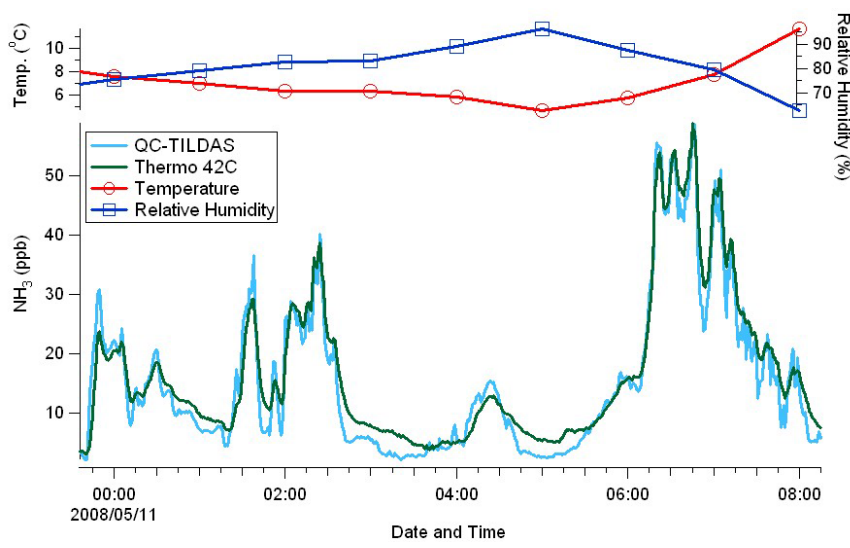

Fig. 7a. Time series of CARE observations of temperature and relative humidity and the response of the QC-TILDAS and Thermo 42CTL, both averaged to one minute. The inlet used for the QCTILDAS results in a faster response to changes in ambient $\mathrm{NH}_{3}$ mixing ratio.

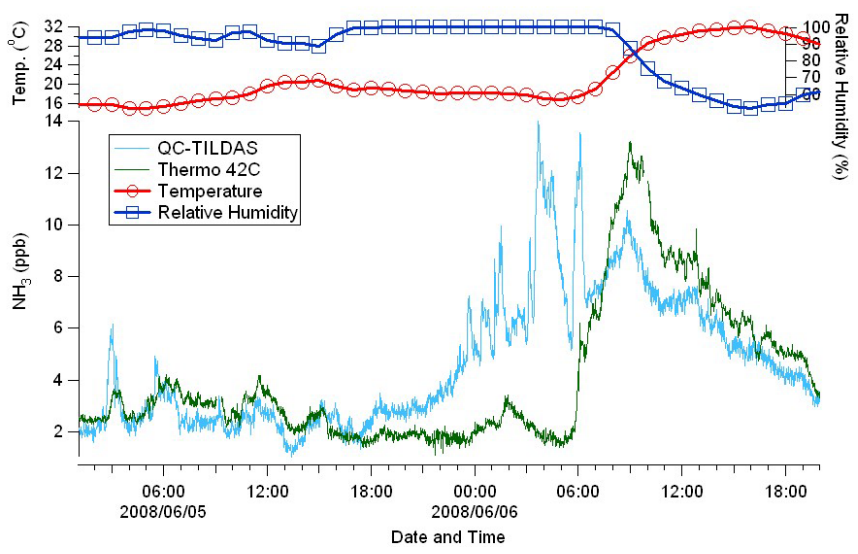

Fig. 7b. A period of rainfall and high relative humidity where the QC-TILDAS and Thermo 42CTL disagree for several hours may be due to condensation of water and uptake of $\mathrm{NH}_{3}$ in the sampling lines of the Thermo 42CTL, followed by release of $\mathrm{NH}_{3}$ the following morning when the temperature rose and the inlet dried.

$\mathrm{NH}_{3}$ during a suspected fertilization event in the vicinity in the month of May, where the $\mathrm{NH}_{3}$ mixing ratios were some of the highest seen during the study. Temperature and relative humidity during this time are also plotted in the upper trace. Although both instruments respond quickly to fluctuations at higher mixing ratios, the QC-TILDAS responds faster to changes at lower mixing ratios. The Thermo $42 \mathrm{CTL}$ seems to take longer to recover from higher inputs of $\mathrm{NH}_{3}$, and we observe a time response lag where $\mathrm{NH}_{3}$ is de-sorbing from the sampling lines. We have observed this effect in an intercomparison with several other instruments (von Bobrutzki et al., 2010), and believe that the faster time response of the QC-TILDAS can be attributed to the use of the quartz inlet and its ability to minimize gas-surface interactions. The differences in inlet design may also be the reason for the time

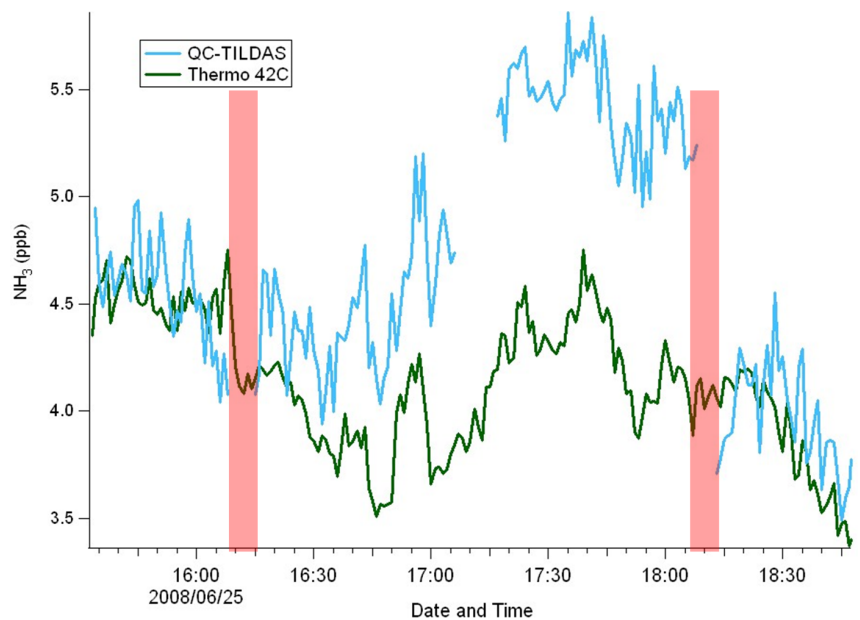

Fig. 7c. Time series of $\mathrm{NH}_{3}$ from the QC-TILDAS and Thermo 42CTL indicate measurement drift for the QC-TILDAS due to changes in the background spectrum, which were not adequately captured with measurements of the background (indicated in red) every two hours.

period outlined in red in Fig. 6 and shown in Fig. 7b where the two instruments did not correlate very well. This period is marked by sporadic precipitation and very high relative humidity ( $\mathrm{RH}>98 \%$ ), which persisted for more than $24 \mathrm{~h}$. The QC-TILDAS reports an increase in $\mathrm{NH}_{3}$ on the evening of 5 June, but the Thermo 42CTL reports an increase in the mixing ratio the following morning when temperatures increase rapidly to $32^{\circ} \mathrm{C}$, the highest observed during the study. One of the reasons for this instrumental offset may be that the prolonged high humidity following rainfall on the previous day prevented evaporation of condensed water on the sampling intake of the Thermo 42CTL. However a visual inspection of the filter and sampling lines of the Thermo 42CTL for condensation was not performed. If condensation was present, when the temperature rose the following morning and the Thermo 42CTL inlet was dried, it may have released $\mathrm{NH}_{3}$ trapped on the surface, leading to a delayed increase in mixing ratio. Norman et al. (2009) also observed losses due to condensation and uptake of $\mathrm{NH}_{3}$ in the inlet during and after rainfall. The instruments' behaviour in Fig. $7 \mathrm{~b}$ contrasts with that during drier conditions ( $\mathrm{RH}=70-85 \%$ ) shown in Fig. 7a where both instruments respond to changes in $\mathrm{NH}_{3}$ mixing ratios at approximately the same time. There may be other reasons for the apparent offset in Fig. 7b, since other shorter periods of rain during the study did not cause discrepancies in mixing ratios between the two instruments. Since this specific time period was the only time during the study when high relative humidity and rainfall persisted for more than several hours, we cannot conclude that every high relative humidity and rain event will lead to an offset.

Part of the scatter in the correlation plot may also be due to background effects in the QC-TILDAS. Figure 7c displays 
a time period where both instruments are initially agreeing, but the QC-TILDAS measurement tends to drift upward over time. It is not until another background is performed, indicated in the plot by the red line, that the QC-TILDAS baseline is brought back down. This suggests that performing a background every $2 \mathrm{~h}$ is not sufficient to capture the changes in the background spectrum. Indeed, it is the case that when the QC-TILDAS was performing backgrounds every $15 \mathrm{~min}$ at the beginning of the study, the correlation was much higher $\left(R^{2}=0.93\right)$. Longer, less frequent backgrounds were adopted to conserve zero air cylinder resources and maximize ambient data acquisition; however more frequent backgrounds appear to be necessary when the background spectrum is variable in time due to changing instrument conditions.

\section{Conclusions}

A Quantum Cascade Tunable Infrared Laser Differential Absorption Spectrometer (QC-TILDAS) was compared in a laboratory study with a Tunable Diode Laser Absorption Spectrometer (TDLAS) and during a two month field study with a Thermo 42CTL chemiluminescence based analyzer. The QC-TILDAS was found to underestimate the $\mathrm{NH}_{3}$ mixing ratio when compared to both instruments due to significant laser line shape distortion when operating the QCL above threshold. As the distortion and underestimation is constant at a given laser output voltage, we can easily correct data using automatic in-field calibrations.

During the laboratory study, dry, humidified and heated lines were tested to determine what affects $\mathrm{NH}_{3}$ adsorption to sample tubes. We observed an increase in the relative importance of $\mathrm{NH}_{3}$ surface interactions at mixing ratios lower than $100 \mathrm{ppb}$, which further increased when sampling humid air as opposed to dry nitrogen. The $\mathrm{NH}_{3}$ surface interactions were lessened by heating the line, where $>95 \%$ of the $\mathrm{NH}_{3}$ decay would occur during the time required for gas volume exchange in the system.

During the field intercomparison, inlet differences resulted in faster time response to changes in $\mathrm{NH}_{3}$ mixing ratios for the QC-TILDAS when compared to the Thermo 42CTL. The Thermo 42CTL may be more susceptible to bias during rapid changes in relative humidity and temperature. The QC-TILDAS measurements were found to suffer from drift when less frequent backgrounds were applied. These differences contributed to the scatter observed in the correlation plot $\left(R^{2}=0.85\right.$, slope $\left.=1.031 \pm 0.002\right)$. Both studies indicate that backgrounds would be most optimally performed frequently, and by removing $\mathrm{NH}_{3}$ from ambient air while keeping the humidity constant, rather than by overflowing the inlet with dry nitrogen or zero air.
Acknowledgements. The authors would like to thank Dave Dow from Agriculture and Agri-Food Canada for construction of the heated lines, along with Mark Zahniser, Dave Nelson and Barry McManus from Aerodyne Research Inc for their helpful support and suggestions. Funding for the QC-TILDAS was provided by the Canadian Foundation for Innovation and the Ontario Research Fund.

Edited by: H. Harder

\section{References}

Asman, W. A. H., Sutton, M. A., and Schjorring, J. K.: Ammonia: emission, atmospheric transport and deposition, New Phytol., 139, 27-48, 1998.

Cantrell, C. A.: Technical Note: Review of methods for linear leastsquares fitting of data and application to atmospheric chemistry problems, Atmos. Chem. Phys., 8, 5477-5487, 2008, http://www.atmos-chem-phys.net/8/5477/2008/.

Cheng, Y.-H. and Tsai, C.-J.: Evaporation loss of ammonium nitrate particles during filter sampling, J. Aerosol Sci., 28, 1553-1567, 1997.

Chow, J. C., Watson, J. G., Lowenthal, D. H., Egami, R. T., Solomon, P. A., Thuillier, R. H., Magliano, K., and Ranzieri, A.: Spatial and temporal variations of particulate precursor gases and photochemical reaction products during SJVAQS/AUSPEX ozone episodes, Atmos. Environ., 32, 2835-2844, 1998.

Dunlea, E. J., Herndon, S. C., Nelson, D. D., Volkamer, R. M., San Martini, F., Sheehy, P. M., Zahniser, M. S., Shorter, J. H., Wormhoudt, J. C., Lamb, B. K., Allwine, E. J., Gaffney, J. S., Marley, N. A., Grutter, M., Marquez, C., Blanco, S., Cardenas, B., Retama, A., Ramos Villegas, C. R., Kolb, C. E., Molina, L. T., and Molina, M. J.: Evaluation of nitrogen dioxide chemiluminescence monitors in a polluted urban environment, Atmos. Chem. Phys., 7, 2691-2704, 2007,

http://www.atmos-chem-phys.net/7/2691/2007/.

Erisman, J. W., Bleeker, A., Hensen, A., and Vermeulen, A.: Agricultural air quality in Europe and the future perspectives, Atmos. Environ., 42, 3209-3217, 2008.

Fehsenfeld, F. C., Huey, L. G., Leibrock, E., Dissly, R., Williams, E., Ryerson, T. B., Norton, R., Sueper, D. T., and Hartsell, B.: Results from an informal intercomparison of ammonia measurement techniques, J. Geophys. Res.-Atmos., 107(D24), 4812, doi:10.1029/2001JD001327, 2002.

Galloway, J. N., Aber, J. D., Erisman, J. W., Seitzinger, S. P., Howarth, R. W., Cowling, E. B., and Cosby, B. J.: The nitrogen cascade, Bioscience, 53, 341-356, 2003.

Gras, J. L.: A Field Comparison of 2 Atmospheric Ammonia Sampling Techniques, Tellus B, 36, 38-43, 1984.

Grouiez, B., Parvitte, B., Joly, L., and Zeninari, V.: Alternative method for gas detection using pulsed quantum-cascade-laser spectrometers, Opt. Lett., 34, 181-183, 2009.

Herndon, S. C., Zahniser, M. S., Nelson, D. D., Shorter, J., McManus, J. B., Jimenez, R., Warneke, C., and de Gouw, J. A.: Airborne measurements of $\mathrm{HCHO}$ and $\mathrm{HCOOH}$ during the New England Air Quality Study 2004 using a pulsed quantum cascade laser spectrometer, J. Geophys. Res.-Atmos., 112, D10S03, doi:10.1029/2006JD007600, 2007. 
IPCC: Climate Change 2007: The Physical Science Basis: Contribution of Working Group I to the Fourth Assessment Report of the Intergovernmental Panel on Climate Change, edited by: Solomon, S., Qin, D., Manning, M., Chen, Z., Marquis, M., Averyt, K. B., Tignor, M., and Miller, H. L., Cambridge University Press, Cambridge, 996 pp., 2007.

Krupa, S. V.: Effects of atmospheric ammonia (NH3) on terrestrial vegetation: a review, Environ. Pollut., 124, 179-221, 2003.

Li, Y. Q., Schwab, J. J., and Demerjian, K. L.: Measurements of ambient ammonia using a tunable diode laser absorption spectrometer: Characteristics of ambient ammonia emissions in an urban area of New York City, J. Geophys. Res.-Atmos., 111, D10S02, doi:10.1029/2005JD006275, 2006.

Livingston, C., Rieger, P., and Winer, A.: Ammonia emissions from a representative in-use fleet of light and medium-duty vehicles in the California South Coast Air Basin, Atmos. Environ., 43, 3326-3333, 2009.

McManus, J. B., Nelson, D. D., Shorter, J., Zahniser, M., Mueller, A., Bonetti, Y., Beck, M., Hofstetter, D., and Faist, J.: Quantum cascade lasers for open and closed path measurement of atmospheric trace gases, Diode Lasers and Applications in Atmospheric Sensing, 4817, 22-33, 2002.

McManus, J. B., Shorter, J. H., Nelson, D. D., and Zahniser, M. S.: Compact quantum cascade laser instrument for rapid, high sensitivity measurements of trace gases in air, 2007 Ieee Sensors, 1-3, 1341-1344, 2007.

Mukhtar, S., Rose, A., Capareda, S., Boriack, C., Lacey, R., Shaw, B., and Parnell, C.: Assessment of ammonia adsorption onto Teflon and LDPE tubing used in pollutant stream conveyance, Agricultural Engineering International: The CIGR Journal of Scientific Research and Development, BC03012, 2003.

Nelson, D. D., Shorter, J. H., McManus, J. B., and Zahniser, M. S.: Sub-part-per-billion detection of nitric oxide in air using a thermoelectrically cooled mid-infrared quantum cascade laser spectrometer, Appl. Phys. B-Lasers O., 75, 343-350, 2002.

Nelson, D. D., McManus, B., Urbanski, S., Herndon, S., and Zahniser, M. S.: High precision measurements of atmospheric nitrous oxide and methane using thermoelectrically cooled midinfrared quantum cascade lasers and detectors, Spectrochim. Acta A, 60, 3325-3335, 2004.

Norman, M., Spirig, C., Wolff, V., Trebs, I., Flechard, C., Wisthaler, A., Schnitzhofer, R., Hansel, A., and Neftel, A.: Intercomparison of ammonia measurement techniques at an intensively managed grassland site (Oensingen, Switzerland), Atmos. Chem. Phys., 9, 2635-2645, 2009, http://www.atmos-chem-phys.net/9/2635/2009/.

Nowak, J. B., Neuman, J. A., Kozai, K., Huey, L. G., Tanner, D. J., Holloway, J. S., Ryerson, T. B., Frost, G. J., McKeen, S. A., and Fehsenfeld, F. C.: A chemical ionization mass spectrometry technique for airborne measurements of ammonia, J. Geophys. Res.-Atmos., 112, D10S02, doi:10.1029/2006JD007589, 2007.

Pinder, R. W., Adams, P. J., Pandis, S. N., and Gilliland, A. B.: Temporally resolved ammonia emission inventories: Current estimates, evaluation tools, and measurement needs, J. Geophys. Res.-Atmos., 111, D16310, doi:10.1029/2005JD006603, 2006.

Pinder, R. W., Adams, P. J., and Pandis, S. N.: Ammonia emission controls as a cost-effective strategy for reducing atmospheric particulate matter in the eastern United States, Environ. Sci. Technol., 41, 380-386, 2007.
Pope, C. A., Burnett, R. T., Thun, M. J., Calle, E. E., Krewski, D., Ito, K., and Thurston, G. D.: Lung cancer, cardiopulmonary mortality, and long-term exposure to fine particulate air pollution, Jama-J. Am. Med. Assoc., 287, 1132-1141, 2002.

Schwab, J. J., Li, Y. Q., Bae, M. S., Demerjian, K. L., Hou, J., Zhou, X. L., Jensen, B., and Pryor, S. C.: A laboratory intercomparison of real-time gaseous ammonia measurement methods, Environ. Sci. Technol., 41, 8412-8419, 2007.

Shah, S. B., Grabow, G. L., and Westerman, P. W.: Ammonia adsorption in five types of flexible tubing materials, Appl. Eng. Agric., 22, 919-923, 2006.

Steinbacher, M., Zellweger, C., Schwarzenbach, B., Bugmann, S., Buchmann, B., Ordonez, C., Prevot, A. S. H., and Hueglin, C.: Nitrogen oxide measurements at rural sites in Switzerland: Bias of conventional measurement techniques, J. Geophys. Res.Atmos., 112, D11307, doi:10.1029/2006JD007971, 2007.

von Bobrutzki, K., Braban, C. F., Famulari, D., Jones, S. K., Blackall, T., Smith, T. E. L., Blom, M., Coe, H., Gallagher, M., Ghalaieny, M., McGillen, M. R., Percival, C. J., Whitehead, J. D., Ellis, R., Murphy, J., Mohacsi, A., Pogany, A., Junninen, H., Rantanen, S., Sutton, M. A., and Nemitz, E.: Field inter-comparison of eleven atmospheric ammonia measurement techniques, Atmos. Meas. Tech., 3, 91-112, 2010, http://www.atmos-meas-tech.net/3/91/2010/.

Warland, J. S., Dias, G. M., and Thurtell, G. W.: A tunable diode laser system for ammonia flux measurements over multiple plots, Environ. Pollut., 114, 215-221, 2001.

Werle, P., Mucke, R., and Slemr, F.: The Limits of Signal Averaging in Atmospheric Trace-Gas Monitoring by Tunable DiodeLaser Absorption-Spectroscopy (Tdlas), Appl. Phys. B-Photo., 57, 131-139, 1993.

Whitehead, J. D., Longley, I. D., and Gallagher, M. W.: Seasonal and diurnal variation in atmospheric ammonia in an urban environment measured using a quantum cascade laser absorption spectrometer, Water Air Soil Poll., 183, 317-329, 2007.

Whitehead, J. D., Twigg, M., Famulari, D., Nemitz, E., Sutton, M. A., Gallagher, M. W., and Fowler, D.: Evaluation of laser absorption spectroscopic techniques for eddy covariance flux measurements of ammonia, Environ. Sci. Technol., 42, 2041-2046, 2008.

Wiebe, H. A., Anlauf, K. G., Tuazon, E. C., Winer, A. M., Biermann, H. W., Appel, B. R., Solomon, P. A., Cass, G. R., Ellestad, T. G., Knapp, K. T., Peake, E., Spicer, C. W., and Lawson, D. R.: A Comparison of Measurements of Atmospheric Ammonia by Filter Packs, Transition-Flow Reactors, Simple and Annular Denuders and Fourier-Transform Infrared-Spectroscopy, Atmos. Environ. A-Gen., 24, 1019-1028, 1990.

Winer, A. M., Peters, J. W., Smith, J. P., and Pitts, J. N.: Response of Commercial Chemiluminescent No-No2 Analyzers to Other Nitrogen-Containing Compounds, Environ. Sci. Technol., 8, 1118-1121, 1974.

Yokelson, R. J., Christian, T. J., Bertschi, I. T., and Hao, W. M.: Evaluation of adsorption effects on measurements of ammonia, acetic acid, and methanol, J. Geophys. Res.-Atmos., 108(D20), 4649, doi:10.1029/2003JD003549, 2003.

Zhang, Y., Wu, S. Y., Krishnan, S., Wang, K., Queen, A., Aneja, V. P., and Arya, S. P.: Modeling agricultural air quality: Current status, major challenges, and outlook, Atmos. Environ., 42, 3218-3237, 2008 . 